\title{
Analysis of postpartum intrauterine contraceptive devices
}

\author{
Sandhya A. Shrigadhi*, Prabhakar S. Gawandi
}

Department of Obstetrics and Gynaecology, Dr. Vaishampayan Memorial Government Medical College, Solapur, Maharashtra, India

Received: 03 February 2021

Revised: 14 February 2021

Accepted: 15 February 2021

\section{*Correspondence:}

Dr. Sandhya A. Shrigadhi,

E-mail: sandhyashrigadi@gmail.com

Copyright: (c) the author(s), publisher and licensee Medip Academy. This is an open-access article distributed under the terms of the Creative Commons Attribution Non-Commercial License, which permits unrestricted non-commercial use, distribution, and reproduction in any medium, provided the original work is properly cited.

\begin{abstract}
Background: PPIUCDs are the only postpartum family planning method for couples requesting a highly effective and reversible, yet long acting, family planning method that can be initiated during the immediate postpartum in lactating women. The public health benefits from PPIUCDs stemmed from the women's increased accessibility to PPIUCDs following facility births, as PPIUCDs could be offered at health facilities after childbirth. It is an attempt to reduce unmet family planning need. The specific aims of this study were to assess the acceptability, feasibility expulsion rate and complications of PPIUCD insertion among women delivering at term in our institute who were eligible and counselled for PPIUCD.

Methods: Prospective study undertaken at Dr. Vaishampayan memorial government medical college, Solapur, Maharashtra conducted from September 2015 to August 2017. All women undergoing delivery at term in this institute and not having any contraindications for postpartum IUCD insertion were counseled for PPIUCD.

Results: A total 3032 were eligible for PPIUCD insertion and were counseled for the same. 1.97\% women accepted PPIUCD insertion while $98.03 \%$ of them declined insertion. 1124 underwent caesarean section while 1908 had vaginal delivery. Among vaginal delivery group rate of acceptance was $1.20 \%$ while that in caesarean section group was $3.29 \%$.

Conclusions: The present study concluded that overall acceptance of PPIUCD in our institute is $1.97 \%$. Considering fear of complications related to IUCD and partner refusal as major causes of refusal for PPIUCD in our study, emphasis on this aspect during counseling can improve acceptance.
\end{abstract}

Keywords: PPIUCD, Acceptability, Expulsion, Complications, Copper T 380 A

\section{INTRODUCTION}

Postpartum family planning (PPFP) aims to prevent unintended pregnancy and closely spaced pregnancies after childbirth. It can save mothers lives-family planning can prevent more than one-third of maternal deaths. PPFP can also save babies lives-family planning can prevent 1 in 10 deaths among babies if couples space their pregnancies more than 2 years apart. PPFP aims to ensure that women have a method of contraception that they can start before the risk of pregnancy returns after childbirth. Best practice is for the chosen method of contraception to be started before the woman leaves the birthing facility. According to the WHO medical eligibility criteria, an IUCD can be inserted in the 48 hours postpartum, referred to here as a postpartum IUCD (PPIUCD) or after four weeks following a birth. ${ }^{1}$ The most effective reversible methods of contraception are PPIUCDs. Once inserted, their failure rates are extremely low (less than 1 unintended pregnancy per 1000 users within the first year 
of typical use). Unlike other methods of contraception, once IUDs are in place the user needs to do nothing on a regular basis to ensure their effective action. They also need to take steps to get them removed (rather than simply stopping the method) and so continuation rates and pregnancy prevention are high.

In India, PPFP is crucial because of huge unmet need (73\% in first 3 months), birth to birth interval (57.6\% of births had interval of less than 36 months), high vulnerability to unintended pregnancy (due to low awareness). India is scaling up PPIUCD services nationally, with these services already in 19 of 28 states. Unmet need for family planning among currently married women is $13 \% .^{2}$ The PPIUCD is most effective, safe, long-acting, coitus independent and rapidly reversible method of contraception with few side effects. The specific advantages of an IUCD placed in the immediate postpartum period include convenience, saves time and additional visit, safe because it is certain that she is not pregnant at the time of insertion, lower rates of perforation and infection, does not interfere with breast feeding, return of fertility is immediate after an IUD is removed, the woman has an effective method for contraception before discharge from hospital. ${ }^{3}$

\section{Advantages for the service provider or the service delivery site}

Certainty that the woman is not pregnant, saves time as performed on the same delivery table for post placental/intracesarean insertions. Additional evaluations and separate clinical procedure is not required, need for minimal additional instruments, supplies and equipment, convenience for clinical staff, helps relieve overcrowded outpatient facilities thus allowing more women . IUCD is a safe and effective contraceptive option for postpartum women who wish to either space or limit subsequent births. ${ }^{3,5}$

\section{Aim}

The aim of the study was to assess the acceptability, feasibility and expulsion rate of PPIUCD insertion among women delivering at term in this institute who were eligible and counseled for PPIUCD and to evaluate the follow up and outcome.

\section{METHODS}

This is a hospital based prospective study undertaken at Dr. Vaishampayan memorial government medical college, Solapur, Maharashtra institute. All women undergoing delivery at term in this institute and not having any contraindications for postpartum IUCD insertion, counseled for PPIUCD. This study was conducted from September 2015 to August 2017.

\section{Sample size with justification}

Assuming prevalence of acceptance for PPIUCD insertion to be $24 \%$, the maximum error in the estimate we are willing to tolerate (say $\pm 4.65 \%$ ), at confidence level $95 \%$ and power equal to $80 \%$, expected sample size is 620 women delivering at term and counseled for postpartum IUCD insertion during antenatal visits or during early labor.

\section{Inclusion criteria}

All women delivering vaginally or by caesarean section at/or more than 37 weeks of estimated gestational age counseled for postpartum IUCD insertion in antenatal period or during early labor and who consent for participation in the study and follow up and meeting all the eligibility criteria for postpartum IUCD insertion.

\section{Exclusion criteria}

Patients who were excluded are those that refused, patients with puerperal sepsis, unresolved, postpartum hemorrhage, temperature $>38$ degree celsius, tender uterus, tumors distorting the uterine cavity (e.g. fibroids), extensive genital trauma.

All women undergoing delivery at term in this institute not having any contraindications for postpartum IUCD insertion were given information regarding advantages, complications and procedure about immediate postpartum IUCD insertion during antenatal visits or during early labor. Those who selected postpartum IUCD insertion as a method of contraception had copper T380A insertion either within 10 minutes of expulsion of the placenta following a vaginal delivery or intracaesareaninsertion that takes place during a cesarean section after removal of placenta and before closure of uterine incision or within 48 hours after delivery prior to discharge from the postpartum ward. Women were followed up at 6 weeks to assess expulsion or any other complications. If IUCD was removed for any reason, reason for its removal was noted. Transvaginal ultrasonography was performed if the IUCD threads were not visible per vaginum.

\section{Insertion techniques}

\section{Post placental insertion}

The IUCD used was CuT 380A, which was available free of cost in the government program. The IUCD was removed from the insertion sleeve and grasped with the Kelly's placental forceps using no-touch technique. Once it was inserted in to lower uterine segment other hand was moved to abdomen and placed over the fundus and uterus was pushed gently upward to reduce the angle and curvature between the uterus and vagina. The cervical os was then gently inspected for the strings. She was allowed to take rest for some time after the procedure. 


\section{Intracesarean insertion}

IUCD was inserted into the uterus through uterine incision and released at fundus of uterus. Strings ware guided toward the lower uterine segment without disturbing IUCDs fundal position. Enough care was taken not to include IUCD strings during uterine closure.

\section{Prior to discharge}

Type of IUCD and date of insertion were mentioned in her discharge card. Woman was informed about the IUCD side effects. She was told when to return for IUCD follow-up. She was advised to report back for any one of the following complaints like foul smelling vaginal discharge different from the usual lochia, lower abdominal pain, especially if accompanied by not feeling well, fever or chills, suspicion that the IUCD has fallen out.

\section{Statistical methods}

We used statistical package for social sciences (SPSS) 21 statistical software. Data was expressed in frequency and percentage. Chi square or Fisher's exact test was used to find the significance between women who accepted and not accepted PPIUCD with respect to various parameters like age, parity, education (Qualitative data type). These tests were also used to find various parameters like rate of complications such as rate of expulsion, infection, missing threads, excessive bleeding $\mathrm{p} / \mathrm{v}$. All statistical test used at $5 \%$ level of significance. $\mathrm{P}$ value less than 0.05 considered as significant.

\section{RESULTS}

The total number of women delivering at this tertiary care centre during period of September 2015 to August 2017 was 25987. Out of which 3032 were eligible for PPIUCD insertion and were counselled for the same. $1.97 \%$ women accepted PPIUCD insertion while $98.03 \%$ of them declined insertion Figure 1. Those women in whom PPIUCD was inserted were followed up at six weeks. In our study, we found $60 \%$ follow up as women were reminded telephonically about their clinical visit at 6 weeks postpartum for IUCD localization and for complaints if any.

Out of 3032 women, 1134 women received counselling regarding PPIUCD in antenatal period while remaining
1898 were counselled in early labor after admission to labor room. Application of Chi square test showed $\mathrm{p}$ value $0.04(<0.05)$ which is significant. Counselling in early labor had higher rate of acceptance.

Out of 3032 women counselled for PPIUCD 1124 underwent caesarean section while 1908 had vaginal delivery. Application of Chi square test reveals acceptance was significantly higher ( $p$ value <0.001) among women with caesarean section.

Some women had given more than one reason for acceptance. Out of 60 women who accepted PPIUCD, majority accepted as it was reversible and long term.

Out of 3032 women who denied PPIUCD insertion, in $1151(38.06 \%)$ women refused PPIUCD because of fear of complication related to IUCD insertion like pain in abdomen and heavy menstrual bleeding.

In this study, as $40.00 \%$ women had expulsion, it was found to be a significant complication.

Chi square test for statistical significance shows that complication in vaginal insertion is highly significantly more than LSCS insertion.

Intracaesarean PPIUCD insertion group had lower expulsion rate $(10.34 \%)$ than IUCD insertion in vaginal delivery group $(65.21 \%)$ which included women with both post placental and immediate postpartum PPIUCD insertion.

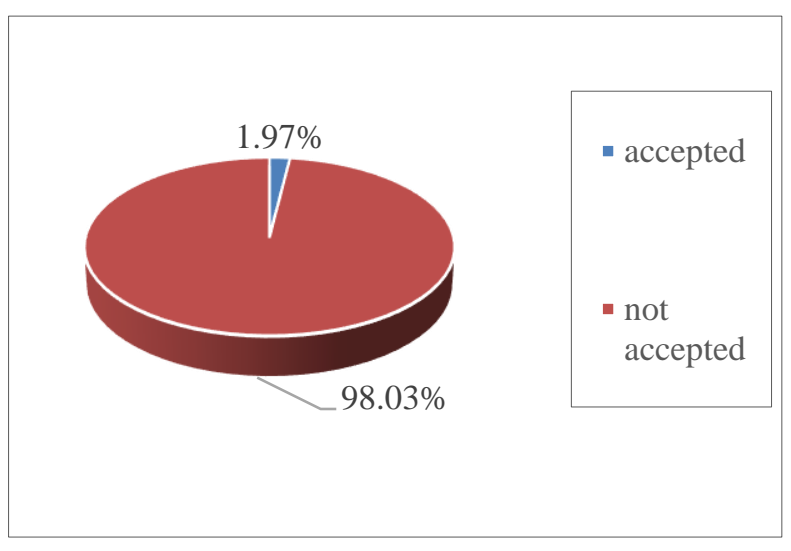

Figure 1: Distribution of women who accepted and not accepted PPIUCD.

Table 1: Distribution of women with respect to time of counselling.

\begin{tabular}{|llcll|}
\hline Time of counseling & $\begin{array}{l}\text { Total women } \\
\text { counseled }\end{array}$ & $\begin{array}{l}\text { Number of } \\
\text { women accepted }\end{array}$ & $\begin{array}{l}\text { Percentage } \\
\text { accepted }\end{array}$ & P value \\
\cline { 1 - 4 } Antenatal & 1134 & 15 & 1.32 & \multirow{2}{*}{$0.04(<0.05)$} \\
\cline { 1 - 4 } In early labor & 1898 & 45 & 2.37 & \\
\hline Total & 3032 & 60 & 1.97 & \\
\hline
\end{tabular}


Table 2: Distribution of women depending on mode of delivery.

\begin{tabular}{|lcllll|}
\hline $\begin{array}{l}\text { Mode of } \\
\text { delivery }\end{array}$ & $\begin{array}{l}\text { Total women } \\
\text { counseled }\end{array}$ & $\begin{array}{l}\text { Number of } \\
\text { women } \\
\text { accepted }\end{array}$ & $\begin{array}{l}\text { Percentage } \\
\text { accepted }\end{array}$ & $\begin{array}{l}\text { Number of } \\
\text { women } \\
\text { declined }\end{array}$ & $\begin{array}{l}\text { Percentage } \\
\text { declined }\end{array}$ \\
\hline LSCS & 1124 & 37 & 3.29 & 1087 & 96.70 \\
\hline Vaginal & 1908 & 23 & 1.20 & 1885 & 98.79 \\
\hline Total & 3032 & 60 & 1.97 & 2972 & 98.02 \\
\hline
\end{tabular}

Table 3: Reasons for acceptance of PPIUCD.

\begin{tabular}{|lll|}
\hline Reason for acceptance & Number of patients & Percentage \\
\hline Reversible & 43 & 71.66 \\
\hline Long term & 34 & 56.66 \\
\hline No remembrance once inserted & 31 & 51.66 \\
\hline Safety & 15 & 25.0 \\
\hline No effect on breast feeding & 13 & 21.66 \\
\hline Previous use of IUCD & 8 & 13.33 \\
\hline Total & 144 & \\
\hline
\end{tabular}

Table 4: Reasons for refusal.

\begin{tabular}{|lll|}
\hline Reason for refusal & Number of women & Percentage \\
\hline Prefer to use another method & 280 & 9.29 \\
\hline Satisfied with previous method of contraception & 193 & 6.39 \\
\hline Fear of pain and heavy bleeding & 1151 & 38.06 \\
\hline Partner refusal & 817 & 26.67 \\
\hline Religious belief & 45 & 1.50 \\
\hline No reason & 546 & 18.03 \\
\hline Total & 3032 & 100.00 \\
\hline
\end{tabular}

Table 5: Distribution of different complications in women with PPIUCD.

\begin{tabular}{|lll|}
\hline Complication & Number of women & Percentage \\
\hline Excessive bleeding & 14 & 35.00 \\
\hline Expulsion complication & 18 & 45.00 \\
\hline Missing threads & 11 & 27.50 \\
\hline Pain in abdomen & 18 & 45.00 \\
\hline
\end{tabular}

Table 6: Correlation between rate of complication and mode of delivery.

\begin{tabular}{|c|c|c|c|c|}
\hline \multirow{2}{*}{ Mode of delivery } & \multicolumn{2}{|c|}{ Complication } & \multirow{2}{*}{ Total } & \multirow{2}{*}{ P value } \\
\hline & Present & Absent & & \\
\hline LSCS & 7 & 30 & 37 & \multirow{3}{*}{$<0.001$} \\
\hline Vaginal & 19 & 4 & 23 & \\
\hline Total & 26 & 34 & 60 & \\
\hline
\end{tabular}

Table 7: Correlation between rate of expulsion and type of insertion.

\begin{tabular}{|lllll|}
\hline Time of insertion & Expulsion & & Total & Percentage \\
\hline Post placental & Present & Absent & & \\
\hline Immediate postpartum & 9 & 7 & 16 & 52.63 \\
\hline Intra cesarean & 5 & 2 & 7 & 75.00 \\
\hline Total & 3 & 34 & 37 & 10.34 \\
\hline
\end{tabular}


Table 8: Distribution of reasons for removal.

\begin{tabular}{|lll|}
\hline Reason for removal & Number of women & Percentage \\
\hline PV bleeding & 1 & 1.66 \\
\hline Pain in abdomen & 1 & 1.66 \\
\hline Partial expulsion & 0 & 0 \\
\hline Social reason & 0 & 0 \\
\hline
\end{tabular}

Table 9: Follow up at 6 weeks.

\begin{tabular}{|lll|}
\hline Follow up at $\mathbf{6}$ weeks & Number of women $(\mathbf{n = 3 6})$ & Percentage \\
\hline Expulsion & 6 & 16.66 \\
\hline IUCD in situ & 30 & 83.33 \\
\hline
\end{tabular}

\section{DISCUSSION}

Though the popularity of immediate postpartum IUCD insertion in countries as diverse as China, Mexico and Egypt support the feasibility of this approach to improve its acceptance in our population it is vital to determine the factors which influence acceptance and refusal of postpartum IUCD as a method of contraception. ${ }^{6}$ In this study, we evaluated the proportion of women accepting PPIUCD and their follow up and outcome.

In our study, out of 3032 counseled women we found acceptance rate of $1.97 \%$. Study conducted in Bundelkhand region in 2014 found $21.77 \%$ acceptance rate. ${ }^{7}$ Acceptance was higher when counseling was done during early labor $(2.37 \%)$ than in antenatal period $(1.32 \%)$. This is in comparison to study of Ashwathy Shanavas, Sujamol Jacob, Nirmala Challamma where percentage of acceptance in early labor $(56 \%)$ was higher than in antenatal period $(44 \%) .{ }^{8}$ Acceptance was higher in caesarean mode of delivery $(3.29 \%)$ than vaginal delivery $(1.97 \%)$. This was in comparison to Rajani Gautam study in 2014 where acceptance was $36.09 \%$ among caesarean delivery and $11.33 \%$ among vaginal mode of delivery. ${ }^{7}$ Among women in whom PPIUCD was inserted, $56.66 \%$ accepted it due to its long term effect, $25 \%$ due its safety, $71.66 \%$ due to reversibility and $51.66 \%$ accepted it because of no remembrance once inserted as it required single time motivation and fewer follow up visits. This shows that postpartum women need a contraceptive method which is long acting, reversible, safe and convenient. $21.66 \%$ women accepted this method because it does not affect lactation. $13.33 \%$ women were satisfied with previous use of IUCD and therefore accepted it again as postpartum contraception also. These were found to be similar to study conducted by Sujanendramishra in 2014 and Rajani Gautam study in 2014. ${ }^{7,9}$ Among 2972 women who declined PPIUCD, $38.06 \%$ of women denied PPIUCD because of fear of heavy bleeding and pain in abdomen due to IUCD. This fear was possibly put into mind of these women by their relatives or friends relating their experiences with IUCD use. So there is need of providing thorough knowledge and proper answers to the questions of women until their satisfaction at the time of counseling so as to eliminate any misbeliefs regarding PPIUCD in their mind.

In our study $26.67 \%$ women refused PPIUCD insertion due to partner refusal. This was observed as one of the major barriers for acceptance of PPIUCD in this study. This finding emphasizes importance of involvement of male partner in counseling. Sujnanendra Mishra in 2014 also found in his study refusal by partner as a dominant reason $\left(50.28 \%\right.$ ) for denial of PPIUCD. ${ }^{9} 29 \%$ preferred to use another contraceptive method, $6.39 \%$ of them were satisfied with previous contraceptive method used and wanted to continue the same. In a study done in Egypt, among the $71.1 \%$ women who refused the IUCD, planning another pregnancy in the near future $(34.3 \%)$ was the most common reason followed by the preference of interval IUCD $(30.2 \%)$ and lactational amenorrhea $(9.3 \%) .{ }^{10}$ Expulsion rates of the immediate PPIUCD at 6 weeks interval was $30 \%$ which compares to the expulsion rate of $5.23 \%$ reported among 210 women included in study in Hubli, India, 1.6\% among 3000 women in a hospital in Paraguay and 3.6\% among women included in study by Somesh Kumar. ${ }^{5,11,12}$

In this study, out of 60 women with postpartum IUCD insertion, expulsion was noticed in 9 women with post placental insertion, 6 with immediate postpartum insertion and 3 case of expulsion in intracesarean insertion. $\mathrm{P}$ value $<0.001$ using Chi square test shows significant correlation between expulsion rate with type of insertion with lower expulsion rate observed in intracesarean insertion when compared to PPIUCD insertion in vaginally delivered women, while post placental insertion had lower expulsion rate than immediate postpartum insertion. Similar findings were observed in a study done in Mexico where at 1 year of follow-up, expulsion rates were $9 \%$ and $13 \%$ for immediate post placental insertion after cesarean and vaginal delivery, respectively and $4 \%$ and $12 \%$ for delayed postpartum insertion, respectively. ${ }^{13}$ In contrast to this finding no significant difference was found in expulsion rates for the immediate and delayed group, which were 2.4 and 2.6 per 100 women years, respecttively in a study conducted in Egypt. ${ }^{14}$ 
Most of the studies which compared expulsion rates in different types of PPIUCD insertion had period of follow up different from our study. But the finding of expulsionrate being higher after immediate postplacental insertion (within 48-72 hours of delivery) than immediate postpartum insertion is similar as in our study. Thus, limitation of our study was that women should have been followed up on long term basis so as to estimate cumulative expulsion rate in different types of PPIUCD insertion. We found very less expulsion in women with intra caesarean insertion of PPIUCD when compared to expulsion rate of $82.3 \%$ in vaginal delivery insertion group which included women with both post placental and immediate postpartum insertions at 6 weeks. This shows that intracesarean insertion of PPIUCD had lower expulsion rate than that in vaginal delivery insertion group. Similar results were found in studies Lara $\mathrm{R}$ et al in 1989 and Ricalde RL et al in 2006. ${ }^{15,16}$ But as already explained shorter follow up being limitation of our study, this result requires evaluation on long term follow up basis.

In our study, out of 60 PPIUCD insertions, 37 were in intracesarean group while remaining 23 were done in vaginal delivery group. Out of 37 women with intracesarean insertion of PPIUCD, 4 developed complications. Similarly out of 23 in vaginal delivery group, 19 developed complications. P-value is $<0.001$ (highly significant) after applying Chi-square test. Thus there is statistical association between occurrences of complications with mode of delivery. Chi square test for statistical significance shows that complication in vaginal insertion is highly significantly more than LSCS insertion.

Out of 60 women who had PPIUCD insertion, excessive $\mathrm{p} / \mathrm{v}$ bleeding $(35.00 \%)$ was found to be the most common complication at follow up visit. These women were reassured and treated with tranexamic acid. Out of 14, 11 women responded to treatment and continued with PPIUCD while 2 women requested removal of it. Pain in abdomen was noticed in $18(45 \%)$ women. In our study we did not encountered with complications like infection and perforation of uterus. These findings support the safety of IUCD insertion in postpartum period. Similar conclusion was drawn by Sujnanendra Mishra in his study. ${ }^{9}$ He found PPIUCD demonstrably safe, with no reported incidence of perforation with low rates of expulsion, pelvic infection and few lost strings. $27.5 \%$ women among those inserted with PPIUCD had lost strings at six weeks. In this study, $60 \%$ follow up of women with PPIUCD insertion were seen. Among them $16.66 \%$ had expulsion of PPIUCD and $83.33 \%$ had IUCD in situ, which was confirmed by pelvic USG.

\section{Limitations of the study}

Expulsion rate and other complications were assessed at 6 weeks in our study. Follow up on long term basis is required to evaluate cumulative expulsion rate, rate of removal for various reasons and actual continuation of this method with satisfaction. Further studies could be conducted that involved one or two years follow up assessments.

\section{CONCLUSION}

The present study concluded that overall acceptance of PPIUCD in our institute is $1.97 \%$. Various factors like parity, partner refusal and fear of side effects of PPIUCD affected acceptance of PPIUCD. Even though majority of women in our study had primary level of education, proper counselling can improve acceptance even in women with less education. Considering fear of complications related to IUCD and partner refusal proved to be major causes of refusal for PPIUCD in our study, emphasis on this aspect during counselling can improve acceptance. Acceptable expulsion rate and absence of complications like uterine perforation and infection, advantages of IUCD such as absence of systemic side effects, convenience as it requires less follow up visits, availability of CuT 380A free of cost by government of India makes application of this approach feasible. Intracesarean PPIUCD insertion was found to be more effective as it had higher acceptance rate and lower expulsion rate.

The provision of PPIUCD is feasible and safe approach. Appropriate counselling can eliminate fear of complications associated with IUCD use and increase acceptance in women even with less education. Involvement of male partner in counselling can play a pivotal role in improving acceptance of PPIUCD. To improve acceptance of PPIUCD strategies to increase public awareness of the PPIUCD through different media sources should be developed. Modification of inserter available with $\mathrm{CuT}$ by increasing its length could make IUCD insertion easier.

\section{ACKNOWLEDGMENTS}

Thanks to department of obstetrics and gynecology, Dr. Vaishampayan memorial government medical college, Solapur for providing copper T380A IUCD free of cost and the Kelly's placental forceps.

\section{Funding: No funding sources \\ Conflict of interest: None declared}

Ethical approval: The study was approved by the Institutional Ethics Committee

\section{REFERENCES}

1. World Health Organization. Medical Eligibility Criteria for Contraceptive Use. Geneva World Health Organization, 2010.

2. Bhat PNM, Arnold F, Gupta K, Kishor S, Parasuraman S, Arokiasamy P, et al. India: National Family Health Survey (NFHS-3). Int Inst Populat Sci Macro Int. 2007;1. 
3. India. Postpartum IUCD reference manual: Family Planning Division, Ministry of Health and Family Welfare, Government of India; New Delhi 2010.

4. Stoddard A, McNicholas C, Peipert JF. Efficacy and safety of long-acting reversible contraception. Drugs. 2011;71(8):969-80.

5. Kittur S, Kabadi YM. Enhancing contraceptive usage by post-placental intrauterine contraceptive devices (PPIUCD) insertion with evaluation of safety, efficacy and expulsion. Int $\mathrm{J}$ Reprod Contracept Obstet Gynecol. 2012;1:26-32.

6. Grimes DA, Lopez LM, Schulz KF, Van-Vliet HA, Stanwood NL. Immediate post-partum insertion of intrauterine devices. Cochrane Database Syst Rev. 2010;(5):003036.

7. Gautam R, Arya KN, Kharakwal S, Singh S, Trivedi M. overview of immediate PPIUCD application in Bundelkhand Region. J Evol Med Dental Sci. 2014;3(36):9518-26.

8. Aswathy S, Jacob S, Nirmala C. Outcome of immediate postpartum intrauterine contraceptive device in caesarean versus vaginal insertion: a comparative study. Int J Reprod Contracept Obstet Gynecol. 2017;6(2):694-9.

9. Sujnanendra M. Evaluation of safety, efficacy, and expulsion of post-placental and intra-cesarean insertion of intrauterine contraceptive devices (PPIUCD). J Obstet Gynaecol India. 2014;64(5):337-43.

10. Mohamed SA, Kamel MA, Shaaban OM, Salem HT. Acceptability for the use of postpartum intrauterine contraceptive devices. Med Principle Pract. 2003;12:170-5.

11. Araujo VB, Ortiz L, Smith J. Postpartum IUD in Paraguay: a case Series of 3000 cases. Contraception. 2012;86:173-86.

12. Kumar S, Sethi R, Balasubramaniam S, Charurat E, Lalchandani K, Semba R, et al. Women's experience with postpartum intrauterine contraceptive device use in India. Reproductive Health. 2014;11:32.

13. Kapp N, Curtis KM. Intrauterine device insertion during the postpartum period: a systematic review. Contraception. 2009;80(4):327-36.

14. El-Shafei MM, Mashali A, Hassan EO, El-Boghdadi L, El-Lakkany N. Postpartum and postabortion intrauterine device insertion unmet needs of safe reproductive health: three years experience of a Mansoura university hospital. Egypt Society Obstet Gynecol. 2000;26:253-62.

15. Lara R, Sánchez RA, Aznar R. Application of intrauterine device through the incision of the cesarean section. Ginecol Obstet Mex. 1989;57:23-7.

16. Ricalde RL, Tobías GM, Pérez CR, Ramírez NV. Random comparative study between intrauterine device Multiload Cu375 and Tcu 380a inserted in the postpartum period. Ginecol Obstet Mex. 2006;74(6):306-11.

Cite this article as: Shrigadhi SA, Gawandi PS. Analysis of postpartum intrauterine contraceptive devices. Int J Reprod Contracept Obstet Gynecol 2021;10:1856-62. 